\title{
Artelogie
}

Recherche sur les arts, le patrimoine et la littérature de l'Amérique latine

$14 \mid 2019$

Sensibilités : Arts, littératures et patrimoine en Amérique latine

\section{Apresentação do dossiê "Sensibilidades - artes, literaturas e patrimônio na América Latina}

Antonio Herculano Lopes e Nádia Maria Weber Santos

\section{(2) OpenEdition}

Edição electrónica

URL: http://journals.openedition.org/artelogie/3596

DOI: 10.4000/artelogie.3596

ISSN: 2115-6395

Editora

Association ESCAL

Refêrencia eletrónica

Antonio Herculano Lopes e Nádia Maria Weber Santos, "Apresentação do dossiê "Sensibilidades artes, literaturas e patrimônio na América Latina », Artelogie [Online], 14 | 2019, posto online no dia 31 julho 2019, consultado o 13 setembro 2019. URL : http://journals.openedition.org/artelogie/3596 ; DOI : 10.4000/artelogie.3596

Este documento foi criado de forma automática no dia 13 Setembro 2019.

Association ESCAL 


\title{
Apresentação do dossiê "Sensibilidades - artes, literaturas e patrimônio na América Latina
}

\author{
Antonio Herculano Lopes e Nádia Maria Weber Santos
}

1 O dossiê "Sensibilidades - artes, literatura e patrimônio na América Latina" iniciou a ser pensado a partir de um colóquio homônimo que ocorreu na Fundação Casa de Rui Barbosa, no Rio de Janeiro, nos dias 23 e 24 de agosto de 2018. O Colóquio interdisciplinar sobre sensibilidades - artes e patrimônio na América Latina reuniu onze pesquisadores de áreas diversas, que tomaram como perspectiva os sentidos, as emoções e as sensibilidades no estudo e interpretação de processos históricos e sociais, interessados na interdisciplinaridade e no desenvolvimento de conceitos e metodologias para esse "mundo do sensível".

Desde sua emergência como objeto da investigação histórica, de Johan Huizinga às considerações de Lucien Febvre, ou, entre nós, o ensaísmo de Gilberto Freyre e Sérgio Buarque de Holanda, o tema das sensibilidades exerce sobre o olhar dos historiadores e cientistas sociais um desafiante fascínio, contrabalançado pela dificuldade de incorporação ao discurso mais "controlado" da disciplina que parece destiná-lo a uma posição de marginalidade. A sensibilidade faz parte das categorias que abrem o discurso para o indizível. Uma das marcas de identificação do indivíduo moderno, nem por isso ela deixa de ser apreensível em sua dimensão social: ao contrário, revela-se instância estratégica na construção social e histórica da subjetividade, passando do singular ao plural ou a uma história das sensibilidades. É comum que a escrita da história pressuponha a racionalidade do historiador e da produção das fontes. Se, nas últimas décadas, tem-se dado mais atenção aos fatores subjetivos que marcam a análise historiográfica, é mais raro o empenho em surpreender a marca das emoções nas próprias fontes que informam a pesquisa. Os arquivos (textuais, imagéticos, sonoros) se apresentam como portadores de "dados", velando a marca deixada por mulheres e homens de carne e osso, com suas sensações e emoções. Tal análise, difícil, porém necessária, é capaz de apontar para formas de ser e de sentir muito distintas das do tempo 
do historiador, permitindo-lhe adentrar melhor num mundo no limite para sempre perdido.

3 A partir de nossas experiências em reuniões da Anpuh Nacional (o encontro historiadores brasileiros, que acontece a cada dois anos), enquanto coordenadores de simpósios temáticos sobre as sensibilidades na história, entendemos esse colóquio como um momento de estreitar laços teóricos e metodológicos com pesquisadores que se interessam pelo campo, interdisciplinar por excelência, das sensibilidades. Embora partamos da história cultural, com conceitos como representações e imaginário, com a discussão sobre as narrativas histórica e ficcional e com a própria questão das sensibilidades, sabemos que outras áreas pensam e discutem com instrumentais próprios as formas sensíveis de fazer face à realidade e de interpretá-la. Compreendemos que as artes, a literatura, o patrimônio, a ciência e as diversas formas de pensamento podem se tornar espaços teóricos e temáticos privilegiados para a discussão interdisciplinar. Daí a ideia de reunir um grupo de pesquisadores de formação variada com este desafio: pensar em conjunto como trabalhamos e o que ganhamos com o tema das sensibilidades.

4 Assim, ampliando o escopo para intelectuais de outras áreas, o dossiê é composto por pesquisadores que fazem leituras de como artistas, cientistas e pensadores deixaram a marca dos seus afetos e percepções em suas produções, relacionadas à América Latina como um todo. Acrescentamos, ainda, em nossas reflexões, a relação entre sensibilidade e memória, tão presente nas preocupações de pesquisadores atuais. Nosso propósito foi usar a perspectiva das sensibilidades individuais e dos grupos como forma de chegar ao real em construção e às ideias que dele fazem parte. Os arquivos pessoais também são fontes particularmente preciosas para esse tipo de trabalho, porém, a própria produção intelectual e artística pode fornecer elementos relevantes para leituras que busquem as relações entre o indivíduo e a sociedade, entre as representações e as práticas ou entre a subjetividade e a realidade. Nessa senda, também retomamos como suporte teórico de nossas discussões os textos da historiadora Sandra Pesavento sobre sensibilidades, a qual foi uma das pioneiras desse campo no Brasil.

Os dez autores e seus textos discorrem sobre marcos conceituais e metodologias; desafios de pesquisa sobre sensibilidades em arquivo; tabus e paixões; simbolismo e heroísmo; solidão, melancolia e tango; infância e crítica social na poesia peruana; teatralidade como instinto e forma de conhecimento; favelas e dramaturgia brasileira; viajantes, índios e suas relações; a presença inglesa na crítica da literatura latino-americana; sensibilidades jornalísticas.

6 São eles: Rosalina Estrada Urroz (Benemérita Universidad Autónoma de Puebla, México) Tabúes y pasiones: ideas, afectos y prácticas en el cruce del Atlántico; Antonio Herculano Lopes (FCRB) - Algumas ideias para um marco conceitual sobre as sensibilidades nas ciências humanas; Nádia Maria Weber Santos (IHGRGS/UFG) e Maximiano Martins de Meireles (Uneb) - A temática das sensibilidades no arquivo pessoal da historiadora Sandra Jatahy Pesavento: possibilidades e desafios de pesquisa no campo das sensibilidades; Carlos Velázquez (Unifor) - ¿Y ahora, quién podrá defendernos? Sobre heroísmo demoniaco en América Latina; Avelino Romero Simões Pereira (Unirio) - "Cafetín de Buenos Aires", uma janela sobre a cidade moderna: solidão e melancolia na experiência do tango dos anos $1930 \mathrm{e}$ 40; Alejandra Josiowicz (CPDOC/FGV) - Para uma estético-política da infância: experimentação e crítica social em César Vallejo; Robson Corrêa de Camargo (UFG) - A teatralidade na arte brasileira, antropófagos e antropofagias; Maria de Fátima Costa (UFMT) Os "meninos índios" que Spix e Martius levaram a Munique; Daniel Lago Monteiro (USP) - O 
solo da transição: William Hazlitt e a literatura latino-americana; Joëlle Rouchou (FCRB) Joel Silveira, repórter de Diretrizes.

7 Importante é, ao situarmo-nos em campo de investigação tão complexo quanto profícuo, salientar que a produção historiográfica e científica em geral das ciências humanas e sociais tem feito um extraordinário esforço de expansão de seus temas, fontes e perspectivas, permitindo leituras mais complexas do fenômeno social. Nesse movimento, cresceu uma atenção mais específica ao campo das sensibilidades, capaz de perceber algo do que se perde diante do documento "frio" - a paixão, as fantasias, os desejos e os medos que movem homens e mulheres em suas ações. A subjetividade, traduzida muitas vezes pelas sensibilidades a determinados fatos, por sua vez, está no seio de toda e qualquer manifestação humana. Ela é um produto não apenas da história individual, mas, também, da história coletiva do homem, de sua cultura. As ciências humanas e sociais, atualmente e cada vez mais, admitem que, enquanto humanos, os sentidos, as emoções e as sensibilidades estão no fundamento de nossas relações com os outros e com o mundo que nos rodeia, assim como nos modos de vida e de interação. É sobre essas complexas redes de subjetividades, afetos e sentidos que os textos deste dossiê refletem, na expectativa de oferecer uma leitura prazerosa sobre a temática "sensibilidades na América Latina".

\section{RESUMOS}

O dossiê "Sensibilidades - artes, literatura e patrimônio na América Latina" iniciou a ser pensado a partir de um colóquio homônimo que ocorreu na Fundação Casa de Rui Barbosa, no Rio de Janeiro, nos dias 23 e 24 de agosto de 2018. O dossiê tenta, com a colaboração de pesquisadores de diferentes domínios, tomar como perspectiva os sentidos, as emoções e as sensibilidades no estudo e interpretação de processos históricos e sociais, interessados na interdisciplinaridade e no desenvolvimento de conceitos e metodologias para esse "mundo do sensível".

Le dossier «Sensibilités : Arts, littérature et patrimoine en Amérique latine» tente d'analyser les sens, les émotions et les sensibilités dans l'étude et l'interprétation des processus historiques et sociaux, avec la collaboration de chercheurs de domaines différents s'intéressant à l'interdisciplinarité et au développement de concepts et de méthodologies pour ce "monde du sensible".

\section{ÍNDICE}

Mots-clés: Sensibilités, arts, littératures, patrimoine, Amérique latine.

Palavras-chave: Sensibilidades, artes, literatura, patrimônio, América Latina. 


\section{AUTORES}

\section{ANTONIO HERCULANO LOPES}

Fundação Casa de Rui Barbosa. Pesquisador em história.

\section{NÁDIA MARIA WEBER SANTOS}

Médica, psiquiatra junguiana e historiadora. Possui Mestrado e Doutorado em História pela UFRGS e Pós-Doutorado pela Université Laval (Québec/Canadá). É bolsista de produtividade do CNPq nível 2 desde 2016. É membro pesquisadora do Instituto Histórico e Geográfico do Rio Grande do Sul e curadora do Acervo Sandra Jatahy Pesavento nesta instituição. Integra o comitê editorial da revista Artelogie, vinculada ao CRAL/EFISAL - EHESS de Paris. Atualmente é professora do PPG em Performances Culturais da UFG (Universidade Federal de Goiás). 